\title{
From the Desk of Editor-in- Chief
}

\section{S. R. Bhatt ${ }^{1}$}

Published online: 8 February 2019

(c) ICPR 2019

This issue of JICPR Vol. 36, No 1 January 2019 is in your hand. We sincerely thank all the learned contributors.

Philosophy has been recognized as a foundational discipline and has its avowed task to provide needed guidance to all other disciplines. Philosophising has to take cognizance of both its theoretical foundation and its applied dimension.

In a philosophical enterprise, there has to be a holistic and integral approach. Special attention can be paid to any particular domain of philosophizing, but it has to be directly or indirectly in coordination with other domains. Reflections in one domain should be not only in harmony with reflections in other domains, but should also benefit in doing reflections in other domains.

In any meaningful exercise, one has to be clear with regard to objective (prayojana) and result (phala) apart from the subject matter and methodology. There has to be coherence and logicality in thinking, but it has to be based on concrete experiences preferably of one's own. To use a Sanskrit term, it should be svasthita. But if it is borrowed one, it must be assimilated with a critical understanding. Professor K.C. Bhattacharya's advice given in the paper "Swaraj in Ideas" is worth emulation. If past heritage is banked upon, it has to be done with a judicious mind and in the form of creative reinterpretation in keeping with the needs and aspirations of the given time. It is hoped that philosophical enterprise is undertaken with an objective of meaningful purpose.

\section{S. R. Bhatt}

jicpr.editor@gmail.com

1 Indian Council of Philosophical Research, New Delhi, India 